\title{
Volatile $\mathrm{C}_{6}$-Aldehyde Formation via Hydroperoxides from $\mathrm{C}_{18}$-Unsaturated Fatty Acids in Etiolated Alfalfa and Cucumber Seedlings
}

\author{
Jiro Sekiya, Tadahiko KaJiwara and Akikazu HatanakA \\ Department of Agricultural Chemistry, Faculty of Agriculture, \\ Yamaguchi University, Yamaguchi 753
}

Received September 28, 1978

1. Etiolated seedlings of alfalfa and cucumber evolved $n$-hexanal from linoleic acid and $c i s-3$-hexenal and trans-2-hexenal from linolenic acid when they were homogenized.

2. The activities for $n$-hexanal formation from linoleic acid, lipoxygenase and hydroperoxide lyase were maximum in dry seeds and $1 \sim 2$ day-old etiolated seedlings of alfalfa, and in $6 \sim 7$ day-old etiolated seedlings of cucumber.

3. $n$-Hexanal was produced from linoleic acid and 13-hydroperoxylinoleic acid by the crude extracts of etiolated alfalfa and cucumber seedlings. cis-3-Hexenal and trans-2-hexenal were produced from linolenic acid and 13-hydroperoxylinolenic acid by the crude extracts of etiolated alfalfa and cucumber seedlings. But these extracts, particularly cucumber one, showed a high isomerizing activity from cis-3-hexenal to trans-2-hexenal,

4. When the $\mathrm{C}_{\mathrm{B}}$-aldehydes were produced from linoleic acid and linolenic acid by the crude extracts, formation of hydroperoxides of these $\mathrm{C}_{18}$-fatty acids was observed.

5. When 9-hydroperoxylinoleic acid was used as a substrate, trans-2-nonenal was produced by the cucumber homogenate but not by the alfalfa homogenate.

6. As the enzymes concerned with $\mathrm{C}_{b}$-aldehyde formation, lipoxygenase was partially purified from alfalfa and cucumber seedlings and hydroperoxide lyase, from cucumber seedlings. Lipoxygenase was found in a soluble fraction, but hydroperoxide lyase was in a membrane bound form. Alfalfa lipoxygenase catalyzed formation of 9- and 13-hydroperoxylinoleic acid $(35: 65)$ from linoleic acid and cucumber one, mainly 13-hydroperoxylinoleic acid formation. Alfalfa hydroperoxide lyase catalyzed $n$-hexanal formation from 13-hydroperoxylinoleic acid, but cucumber one catalyzed formation of $n$-hexanal and trans-2-nonenal from 13 - and 9-hydroperoxylinoleic acid, respectively.

7. From the above results, the biosynthetic pathway for $\mathrm{C}_{6}$-aldehyde formation in etiolated alfalfa and cucumber seedlings is established that $\mathrm{C}_{6}$-aldehydes ( $n$-hexanal, cis3-hexenal and trans-2-hexenal) are produced from linoleic acid and linolenic acid via their 13-hydroperoxides by lipoxygenase and hydroperoxide lyase.

$\mathrm{C}_{6}$-Aldehydes such as $n$-hexanal, cis-3hexenal and trans-2-hexenal, which are re-

\footnotetext{
Abbreviations: DCIP, 2, 6-dichlorophenol indophenol; MB, methylene blue; SKF 525-A, 2-dimethylaminoethyl-2, 2-diphenyl valerate; $p$-CMB, $p$-chloromercuribenzoate; GSH, reduced glutathione; 9hydroperoxylinoleic acid, 9-hydroperoxy-octadecatrans-10, cis-12-dienoic acid; 9-hydroxylinoleic acid, 9-hydroxy-octadeca-trans-10, cis-12-dienoic acid: 9hydroperoxylinolenic acid, 9-hydroperoxy-octadecatrans-10, cis-12, cis-15-trienoic acid; 13-hydroperoxyiinoleic acid, 13-hydroperoxy-octadeca-cis-9, trans-11dienoic acid; 13-hydroxylinoleic acid, 13-hydroxyoctadeca-cis-9, trans-11-dienoic acid; 13-hydroperoxylinolenic acid, 13-hydroperoxy-octadeca-cis-9, trans-11, cis-15-trienoic acid.
}

sponsible for major characteristic odor of green leaves, occur in a variety of plants including vegetables and fruits. These are produced from $\mathrm{C}_{18}$-unsaturated fatty acids containing a cis-1, cis-4-pentadiene moiety such as linoleic acid and linolenic acid. ${ }^{(\sim 6)}$ Recently, etiolated watermelon seedlings have been reported to produce $n$-hexanal from linoleic acid via 13hydroperoxide by lipoxygenase and hydroperoxide lyase. ${ }^{7)}$ Similar pathway for $\mathrm{C}_{6}{ }^{-}$ aldehyde formation are reported in tomato fruits $^{8}$ and bean leaves, ${ }^{{ }^{\prime}}$ and for $\mathrm{C}_{6^{-}}$and $\mathrm{C}_{9^{-}}$ aldehydes (cis-3-nonenal, trans-2-nonenal, cis-3, cis-6-nonadienal and trans-2, cis-6- 
nonadienal) in cucumber fruits ${ }^{10 \sim 13)}$ in which $\mathrm{C}_{9}$-aldehydes are major products from $\mathrm{C}_{18^{-}}$ fatty acids. ${ }^{10,11,14,15)}$ However, properties of the enzymes in etiolated seedlings and fruits are not well known.

In the present paper, we describe $\mathrm{C}_{6}$-aldehyde formation mediated by lipoxygenase and hydroperoxide lyase in etiolated alfalfa and cucumber seedlings: changes in the enzyme activities responsible for $\mathrm{C}_{6}$-aldehyde formation during germination, properties of $\mathrm{C}_{6}$-aldehyde formation from $\mathrm{C}_{18}$-unsaturated fatty acids and partial purification and some properties of the concerned enzymes.

\section{MATERIALS AND METHODS}

Plant materials and preparation of the crude extracts. Seeds of alfalfa (Medicago sativa "Common") and cucumber (Cucumis sativus "Suyo") were soaked for $12 \mathrm{hr}$ in tap water, then placed on moistened paper and germinated in the dark at $25^{\circ} \mathrm{C}$. Time zero means dry seeds. Etiolated seedlings obtained were homogenized in a chilled mortar for $10 \mathrm{~min}$ with $50 \mathrm{~mm}$ phosphate buffer, pH 6.0 or 6.5 . These homogenates were referred to as "crude homogenates." The crude homogenates were centrifuged at $15,000 \times g$ for $10 \mathrm{~min}$ and the supernatant solutions thus obtained were referred to as "crude extracts."

\section{Enzyme assays. i) Lipoxygenase activity was} determined from the increase in the absorbance at $234 \mathrm{~nm}$ due to conjugated diene of the hydroperoxide with the reaction mixture containing $0.1 \mathrm{ml}$ of linoleic acid solution prepared by the method of Surrey, ${ }^{18}$ $0.1 \mathrm{ml}$ of enzyme solution and $2.8 \mathrm{ml}$ of $50 \mathrm{~mm}$ phosphate buffer, $\mathrm{pH} 6.0 \sim 6.5$. The lipoxygenase activity was also determined by oxygen uptake polarographically with a Clark oxygen electrode (YSI 4004) at $25^{\circ} \mathrm{C}$ with the reaction mixture containing $0.1 \mathrm{ml}$ of linoleic acid solution $(0.28 \mathrm{mg}$ in $0.2 \%$ Tween 20 solution), $0.1 \mathrm{ml}$ of enzyme solution and $2.8 \mathrm{ml}$ of $50 \mathrm{~mm}$ phosphate buffer, $\mathrm{pH}$ 6.5. One enzyme unit was defined as the enzyme amount producing $1 \mu \mathrm{mol}$ of hydroperoxide or consuming $1 \mu \mathrm{mol}$ of oxygen per min at $25^{\circ} \mathrm{C}$. ii) Hydroperoxide lyase activity was determined from the decrease in absorbance at $234 \mathrm{~nm}$ at $25^{\circ} \mathrm{C}$ essentially according to the method described previously. ${ }^{7)}$ The standard reaction mixture contained $0.5 \mathrm{ml}$ of 13-hydroperoxylinoleic acid solution, ${ }^{7)} 0.1 \mathrm{ml}$ of enzyme solution and $2.4 \mathrm{ml}$ of $50 \mathrm{~mm}$ phosphate buffer, $\mathrm{pH} 6.0$ or 6.5 . One enzyme unit was defined as the enzyme amount consuming $1 \mu \mathrm{mol}$ of hydroperoxide per min at $25^{\circ} \mathrm{C}$. iii) $C_{B}$-Aldehyde formation from $C_{18}$-fatty acids was determined by the headspace vapor analysis. Method A: a standard reaction mixture consisted of a substrate at the concentration indicated and $10 \mathrm{ml}$ of enzyme solution with $50 \mathrm{~mm}$ phosphate buffer, pH 6.0 or 6.5 , in a $50 \mathrm{ml}$ Erlenmeyer flask with a rubber stopper. Method B: a standard reaction mixture contained $1 \mathrm{ml}$ of linoleic acid (7 $\mu \mathrm{mol})$ or 13-hydroperoxylinoleic acid solution $(6.5$ $\mu \mathrm{mol})$ as a substrate and $1 \mathrm{ml}$ of enzyme solution in $12 \times 105 \mathrm{~mm}$ test tube with a rubber stopper. Reaction mixtures for the methods $\mathrm{A}$ and $\mathrm{B}$ were incubated at $35^{\circ} \mathrm{C}$ for $10 \mathrm{~min}$ after $1 \mathrm{~min}$ shaking at room temperature. Then, $6 \mathrm{ml}$ of headspace vapor was taken and analysed by GLC under the condition described elsewhere. ${ }^{17}$ Amounts of $\mathrm{C}_{6}$-aldehydes were calculated from the standard curve obtained with authentic compounds. ${ }^{13)}$

Preparation of 9- and 13-hydroperoxylinoleic acids and 13-hydroperoxylinolenic acid. 9- and 13-hydroperoxylinoleic acids were prepared from linoleic acid essentially according to the procedure described previously, ${ }^{19)}$ using potato lipoxygenase ${ }^{20,21)}$ and soybean lipoxygenase (Sigma type I), ${ }^{22)}$ respectively. 13-Hydroperoxylinolenic acid was prepared from linolenic acid and soybean lipoxygenase. ${ }^{19,22}$ These hydroperoxides gave a sharp absorbance at $234 \mathrm{~nm}$ and a single spot on silica gel TLC.

Centrifugal fractionation of enzymes in cucumber seedlings. Six day-old etiolated seedlings of cucumber (110 $\mathrm{g}$ in fr. wt.) were homogenized in a Waring blender for $30 \mathrm{sec}$ with $3 \mathrm{vol}$ of grinding buffer: $50 \mathrm{~mm}$ phosphate buffer ( $\mathrm{pH} 7.0$ ) containing $1 \mathrm{~mm} \mathrm{MgCl}, 1 \mathrm{~mm}$ EDTA, $1 \mathrm{~mm}$ GSH and $0.4 \mathrm{~m}$ sucrose. The homogenate was filtered through 2 layers of gauze, and the filtrate was centrifuged at $10,000 \times g$ for $10 \mathrm{~min}$. The supernatant $(10,000 \times g$ supernatant $)$ was again centrifuged at $88,000 \times g\left(R_{\max }\right.$, Hitachi RP 30 A rotor $)$ for $90 \mathrm{~min}$. The fractions thus obtained were referred to as $88,000 \times g$ supernatant and $88,000 \times g$ pellet. The $88,000 \times g$ pellet was suspended gently in a small amount of the grinding buffer and centrifuged at $149,000 \times g$ ( $R_{\operatorname{mex}}$, Hitachi RP 55 rotor) for 60 min to wash 88,000 $\times g$ pellet. The washed $88,000 \times g$ pellet was suspended and homogenized with $50 \mathrm{~mm}$ phosphate buffer, $\mathrm{pH}$ 6.5 , containing $1 \mathrm{~mm}$ GSH and $0.1 \%$ Triton X-100, and stirred gently for $1 \mathrm{hr}$ at $4^{\circ} \mathrm{C}$. Then, the $88,000 \times g$ pellet suspension was centrifuged at $149,000 \times g$ for $90 \mathrm{~min}$. The supernatant and pellet thus obtained were referred to as Triton $X-100$ supernatant and Triton $X-100$ pellet, respectively.

Purification of lipoxygenase. Crude extracts were used as enzyme source. i) Alfalfa. $\left(\mathrm{NH}_{4}\right)_{2} \mathrm{SO}_{4}$ was added to the alfalfa crude extract to bring to $70 \%$ saturation. The mixture was centrifuged at $10,000 \times g$ 
for $20 \mathrm{~min}$ and separated into pellet, supernatant and surface fluffy layer, among which fluffy layer contained $60 \%$ of lipoxygenase activity. The fluffy layer was collected, dissolved in and dialyzed against $10 \mathrm{~mm}$ phosphate buffer, pH 7.5. The dialyzed enzyme solution was applied to CAP-S S $_{1}$ cellulose (trimethylamino-2hydroxypropyl cellulose) column equilibrated with $10 \mathrm{~mm}$ phosphate buffer, pH 7.5 , and eluted with 0 , 0.1 and $0.2 \mathrm{M} \mathrm{NaCl}$ in $10 \mathrm{~mm}$ phosphate buffer, $\mathrm{pH} 6.5$. Lipoxygenase eluted with $0.1 \mathrm{M} \mathrm{NaCl}$ was used as a partially purified enzyme. ii) Cucumber. $\left(\mathrm{NH}_{4}\right)_{2} \mathrm{SO}_{4}$ was added to the cucumber extract to bring to $70 \%$ saturation, and the mixture was centrifuged at $10,000 \times$ $g$ for $20 \mathrm{~min}$. The pellet which contained lipoxygenase was dissolved in and dialyzed against $10 \mathrm{~mm}$ phosphate buffer, $\mathrm{pH}$ 7.5. The dialyzed enzyme was sujected to DEAE cellulose column equilibrated with $10 \mathrm{~mm}$ phosphate buffer, pH 7.5. Lipoxygenase obtained in unadsorbed fraction was precipitated by $\left(\mathrm{NH}_{4}\right)_{2} \mathrm{SO}_{4}$, collected by centrifugation, dissolved in and dialyzed against $10 \mathrm{~mm}$ acetate buffer, $\mathrm{pH}$ 5.5. The dialyzed enzyme solution was applied to $\mathrm{CM}$ cellulose column equilibrated with $10 \mathrm{~mm}$ acetate buffer, pH 5.5 , washed with the same buffer and eluted with $0.125 \mathrm{M} \mathrm{NaCl}$ in $10 \mathrm{~mm}$ acetate buffer, $\mathrm{pH} 5.5$, to yield purified enzyme.

Identification and determination of hydroperoxides of $C_{18}$-fatty acids. The mixture, after lipoxygenase reaction was performed, was acidified to $\mathrm{pH} 3$ with $2 \mathrm{~N}$ $\mathrm{HCl}$ and then extracted with $n$-hexane. The hexane extract was added to excess $\mathrm{NaBH}_{4}$ in aq. $50 \%(\mathrm{v} / \mathrm{v})$ $\mathrm{MeOH}$ adjusted to $\mathrm{pH} 9$ with $50 \mathrm{~mm}$ borate buffer. The mixture under $\mathrm{N}_{2}$ was stirred for $30 \mathrm{~min}$ at room temperature, and diluted with 1 vol of water. After the reaction mixture was acidified to $\mathrm{pH} 3$ with $2 \mathrm{~N} \mathrm{HCl}$, the reduced products including hydroxylinoleic acids were extracted with $\mathrm{Et}_{2} \mathrm{O}$. The $\mathrm{Er}_{2} \mathrm{O}$ extract was removed under $\mathrm{N}_{2}$ after esterification with $\mathrm{CH}_{2} \mathrm{H}_{2}$. The residue thus obtained was subjected to HPLC analysis and methyl 9-and 13-hydroxylinoleates were confirmed by comparison with authentic specimens. HPLC was performed with Shimadzu-Dupont LC-2 using an FD column $(7.9 \times 250 \mathrm{~mm}$, silicic acid derivatives prepared by Shimadzu) and $n$-hexane-EtOH (95:5) as a carrier solvent (flow rate, $2 \mathrm{ml} / \mathrm{min}$ ). Detection was performed by the absorbance at $234 \mathrm{~nm}$.

Detection of hydroperoxides produced from linoleic acid or linolenic acid by the crude extracts of etiolated alfalfa and cucumber seedlings was performed as follows. The reaction mixture, after the reaction was performed with the same reaction mixture as that for the headspace method $\mathrm{A}$, was extracted with $5 \mathrm{ml}$ of $n$-hexane. The hexane extract containing hydroperoxylinoleic acid or hydroperoxylinolenic acid was condensed to $2 \mathrm{ml}$, then $25 \mu 1$ was subjected to HPLC analysis: an FD column, $n$-hexane-EtOH $(80: 20)$ as a carrier solvent (flow rate, $2 \mathrm{ml} / \mathrm{min}$ ) and detection by the absorbance at $234 \mathrm{~nm}$. Under this condition, 9and 13-hydroperoxides could not be separated. Amounts of hydroperoxides were calculated from the standard curve obtained by the same extraction procedures from 13-hydroperoxylinoleic acid dissolved in distilled water.

Protein determination. Protein was determined by the method of Lowry et al., ${ }^{23)}$ after precipitating protein by $5 \%$ trichloroacetic acid, collecting the precipitate by centrifugation and dissolving in $0.2 \mathrm{~N} \mathrm{NaOH}$.

\section{RESULTS}

Changes in the activities of n-hexanal formation, lipoxygenase and hydroperoxide lyase during the germination

Figures 1 and 2 show the changes in the activities of $n$-hexanal formation from linoleic acid, lipoxygenase and hydroperoxide lyase (tentatively termed according to Vick and Zimmerman ${ }^{7}$ ) of the crude extracts during the germination of seeds in the dark. Fresh weight and protein contents increased with the development of germination.

In alfalfa (Fig. 1), $n$-hexanal formation with or without addition of linoleic acid was high in dry seeds and in the early stage ( $1 \sim 2$ day $)$

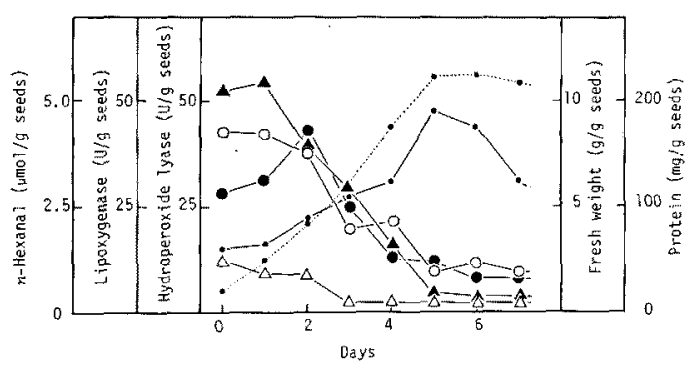

Fig. 1. Changes in the Activities of $n$-Hexanal Formation, Lipoxygenase and Hydroperoxide Lyase of the Crude Extract of Alfalfa during Germination.

(.-.-) shows fresh weight per gram of initial cry seeds (indicated as $\mathrm{g}$ seeds). Crude extract was prepared with 3 vol of $50 \mathrm{~mm}$ phosphate buffer, $\mathrm{pH} 6.5$. (•-) indicates protein content in the crude extract. Activities of lipoxygenase $(0-0)$ and hydroperoxide lyase (-) were determined at $\mathrm{pH} 6.5$ from the increase and the decrease in absorbance at $234 \mathrm{~nm}$, respectively. An amount of $n$-hexanal formed with $(\mathbf{\Delta}-\mathbf{\Lambda})$ or without $(\Delta-\Delta)$ addition of linoleic acid $(70 \mu \mathrm{mol})$ was determined by the headspace method $\mathrm{A}$ at $\mathrm{pH} 6.5$ as in Methods. 
of germination, and then the activity lowered. Lipoxygenase and hydroperoxide lyase activities were also high till the second day, and thereafter lowered. Seedlings germinated for 5 days or more lost their activities completely.

In cucumber (Fig. 2), the activity for $n$ hexanal formation became maximum in 6 dayold seedlings, and no activity was found in dry seeds and less activity in 10 day-old seedlings. Lipoxygenase activity appeared in 2 day-old seedling and then increased rapidly. Hydroperoxide lyase activity began to appear after 5 day-germination and became maxi-

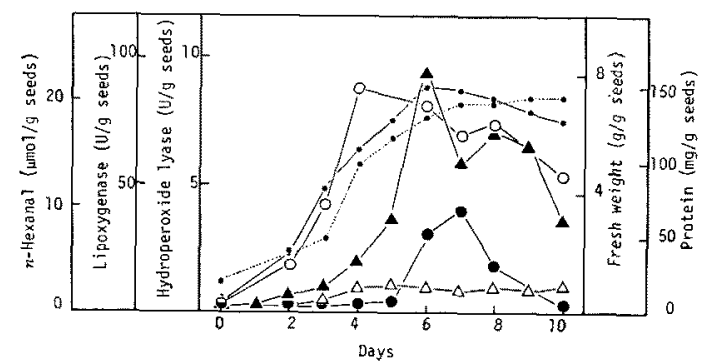

Fig. 2. Changes in the Activities of $n$-Hexanal Formation, Lipoxygenase and Hydroperoxide Lyase of the Crude Extract of Cucumber during Germination.

Symbols and procedures are the same as in Fig. 1 except that $50 \mathrm{~mm}$ phosphate buffer, $\mathrm{pH}$ 6.0, was used. mum in $6 \sim 7$ day-old seedlings. But no activities of lipoxygenase and hydroperoxide lyase could be detected in dry seeds. Thus, the three kinds of activities became maximum in $6 \sim 7$ day-old cucumber seedlings.

\section{$C_{6^{-}}$and $C_{9^{-}}$aldehyde formation from $C_{18^{-}}$} unsaturated fatty acids and their hydroperoxides by the crude homogenates of etiolated seedlings

In order to investigate the $\mathrm{C}_{6^{-}}$and $\mathrm{C}_{9^{-}}$ products from linoleic acid and its hydroperoxides, the crude homogenates of $12 \mathrm{hr}$-old etiolated alfalfa and 6 day-old etiolated cucumber seedlings were incubated with linoleic acid or its hydroperoxides, then the essential oil was prepared and analysed with GLC. ${ }^{14}$ Optimal $\mathrm{pH}$ for $n$-hexanal formation from linoleic acid was $6.0 \sim 6.5$ both for alfalfa and cucumber. Table I shows that $n$-hexanal was produced from linoleic acid by the homogenate of alfalfa and cucumber but not trans-2hexenal from linoleic acid. A small amount of trans-2-nonenal was also produced from linoleic acid with the cucumber homogenate but not with the alfalfa homogenate. When 13-hydroperoxylinoleic acid was used as a substrate, $n$-hexanal was produced in a larger

Table I. $C_{\theta}$-And $C_{8}$-Aldehydes Produced from Linoleic Acid and

Its Hydroperoxides by the Crude Homogenates of Etrolated Alfalfa ANd CuCumber Seedlings

\begin{tabular}{l} 
Substrate added \\
\cline { 2 - 4 } \\
Alfalfa
\end{tabular}


amount than that from linoleic acid in alfalfa and cucumber and no $\mathrm{C}_{9}$-aldehydes were produced in both.

In contrast, when 9-hydroperoxylinoleic acid was used, trans-2-nonenal was produced but not trans-2, cis-6-nonadienal. However, though trans-2-nonenal was produced extremely from 9-hydroperoxide by the cucumber homogenate, alfalfa homogenate gave only a slight amount of trans-2-nonenal. These indicate that $n$-hexanal is produced via 13 -hydroperoxide from linoleic acid by alfalfa and cucumber homogenates and that trans-2-nonenal is produced from 9-hydroperoxylinoleic acid by the cucumber homogenate only.

When linolenic acid was used as a substrate, trans-2-hexenal was produced both by the crude homogenates of alfalfa and cucumber seedlings, and a very small amount of trans- 2 , cis-6-nonadienal was detected in cucumber but not in alfalfa.

$C_{6}$-Aldehyde formation from $C_{18}$-fatty acids and their 13-hydroperoxides by the crude extracts of etiolated seedlings and detection of hydroperoxides produced from $C_{18}$-fatty acids

$\mathrm{C}_{6}$-Aldehyde formation from $\mathrm{C}_{18}$-unsaturated fatty acids and their 13-hydroperoxides and hydroperoxide formation during $\mathrm{C}_{6}$-aldehyde formation from $\mathrm{C}_{18}$-fatty acids were investigated by the headspace method and HPLC analysis, respectively.

Figure 3 shows that $n$-hexanal formation from linoleic acid increased with the increase in linoleic acid added in the range of the concentration tested $(0 \sim 20 \mu \mathrm{mol})$ both in alfalfa and cucumber. However, when 13-hydroperoxylinoleic acid was used as a substrate, the highest $n$-hexanal formation was found with addition of $2 \mu \mathrm{mol}$ of 13-hydroperoxide and, then, $n$-hexanal formation lowered with the increase in 13-hydroperoxide added. This may be due to toxic action of high concentration of 13-hydroperoxylinoleic acid. The formation of hydroperoxylinoleic acid, which could not be identified as 9- or 13-hydroperoxide under this condition performed, was

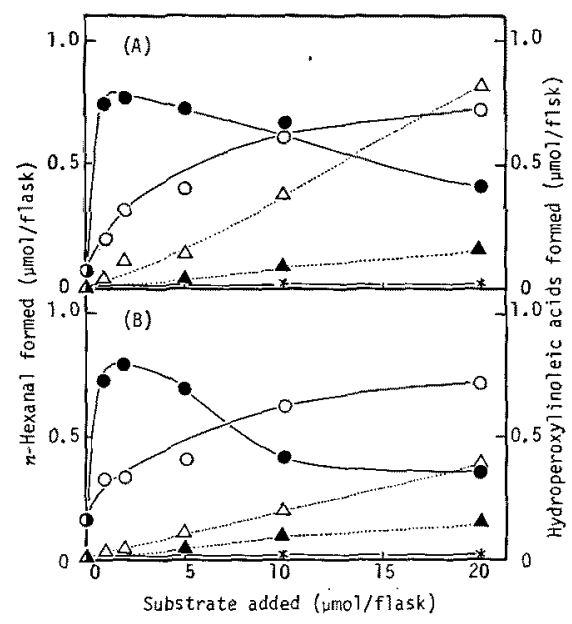

FIG. 3. Formation of $n$-Hexanal and Hydroperoxylinoleic Acid by the Crude Extracts of Etiolated Alfalfa (A) and Cucumber (B) Seedlings.

The crude extracts were prepared from $12 \mathrm{hr}$-old alfalfa and 6 day-old cucumber seedlings with $20 \mathrm{vol}$ of $50 \mathrm{~mm}$ phosphate buffer, $\mathrm{pH} 6.5$. $n$-Hexanal formation was determined by the headspace method $\mathrm{A}$ with addition of the indicated concentration of linoleic acid $(0)$ or 13-hydroperoxylinoleic acid $(\bullet) .(\times)$ shows $n$-hexanal formation from linoleic acid or 13hydroperoxylinoleic acid by heat-treated $\left(100^{\circ} \mathrm{C}\right.$, $10 \mathrm{~min}$ ) crude extracts. Hydroperoxide formation from linoleic acid was determined by HPLC analysis of hexane extract of reaction products as in Methods. $(\Delta)$ shows hydroperoxide formation from linoleic acid with the crude extract and (A), that without the crude extracts.

observed, when linoleic acid was used as a substrate (Fig. 3). The amount of detected hydroperoxylinoleic acid was enough to yield $n$-hexanal obtained from linoleic acid. These results both for alfalfa and cucumber are well consistent with the hypothesis of the $n$-hexanal formation via 13-hydroperoxide from linoleic acid.

When linolenic acid or 13-hydroperoxylinolenic acid was used as a substrate, cis-3-hexenal and trans-2-hexenal were produced as $\mathrm{C}_{6^{-}}$ aldehydes (hexenals) by the crude extracts of alfafa and cucumber, as shown in Table II. In these cases, hexenals were produced with addition of $20 \mu \mathrm{mol}$ of 13-hydroperoxylinolenic acid more than with $2 \mu \mathrm{mol}$ of that both for alfalfa and cucumber unlike $n$-hexanal formation with 13-hydroperoxylinoleic acid. 
TABle III. Formation of cis-3-HeXenal and trans-2-HeXenal from

LINOLENIC ACID AND ITS 13-HYDROPEROXIDE BY $88,000 \times g$

Pellet of Etiolated Cucumber Seedlings

\begin{tabular}{|c|c|c|c|c|c|}
\hline \multirow{2}{*}{ Enzyme } & \multirow{2}{*}{$\begin{array}{l}\text { Substrate } \\
(10 \mu \mathrm{mol})\end{array}$} & \multirow{2}{*}{$\begin{array}{l}\text { Incubation } \\
\text { time (min) }\end{array}$} & \multicolumn{3}{|c|}{ Hexenals formed $(\mu \mathrm{mol} /$ flask $)$} \\
\hline & & & $\begin{array}{c}c i s-3- \\
\text { Hexenal (a) }\end{array}$ & $\begin{array}{l}\text { trans-2- } \\
\text { Hexenal (b) }\end{array}$ & a. 0 \\
\hline \multirow[t]{2}{*}{ None } & Linolenic acid & 10 & trace & trace & - \\
\hline & $\begin{array}{l}\text { 13-Hydroperoxy- } \\
\text { linolenic acid }\end{array}$ & 10 & trace & trace & - \\
\hline \multirow{4}{*}{$\begin{array}{l}88,000 \times g \\
\text { pellet }\end{array}$} & None & 10 & 0 & 0.08 & $0: 100$ \\
\hline & Linolenic acid & 10 & 0.11 & 0.19 & $37: 63$ \\
\hline & 13-Hydroperoxy- & 3 & 1.43 & 0.14 & 91: 9 \\
\hline & linolenic acid & 10 & 0.48 & 0.31 & $61: 39$ \\
\hline
\end{tabular}

A $88,000 \times g$ pellet was prepared from 6 day-old etiolated cucumber seedlings $(35 \mathrm{~g})$ by the procedures as in Methods, then suspended in $60 \mathrm{ml}$ of $50 \mathrm{~mm}$ phosphate buffer, pH 6.5, containing $1 \mathrm{~mm}$ GSH, and used as an enzyme solution. Formation of cis-3-hexenal and trans-2-hexenal was determined by the headspace method A.

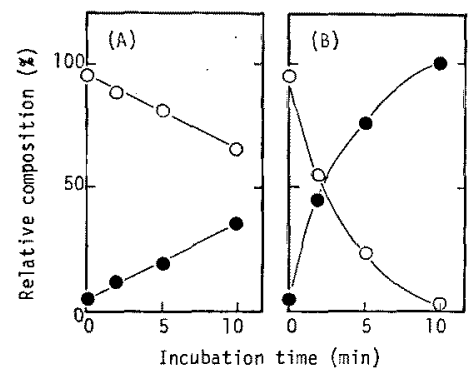

FIG. 4. Isomerization of cis-3-Hexenal to trans-2Hexenal by the Crude Extracts of Etiolated Alfalfa (A) and Cucumber (B) Seedlings.

Relative composition was determined by the headspace method. Ten $\mathrm{ml}$ of the crude extract prepared from $12 \mathrm{hr}$-old etiolated alfalfa seedlings or 6 day-old etiolated cucumber seedlings with $20 \mathrm{vol}$ of $50 \mathrm{~mm}$ phosphate buffer, pH 6.5, was incubated with cis-3hexenal $(6 \mu \mathrm{mol})$ in a $50 \mathrm{ml}$ flask for indicated periods and the products (hexenals) in the headspace vapor were analyzed by GLC. (O) shows cis-3-hexenal and (•), trans-2-hexenal.

$\times g$ pellet as a hydroperoxide lyase rich fraction, as shown in Table III. This may be due to the removal of isomerizing factor involved in the crude extract of cucumber seedlings. In cucumber fruits, a similar result was found that cis-3-nonenal was detected easily without isomerization as the purification of hydroperoxide lyase proceeded.

The formation of $\mathrm{C}_{6}$-aldehydes from $\mathrm{C}_{18}$ unsaturated fatty acids has been reported in green leaves in which the enzyme system is localized in chloroplast lamellae. ${ }^{19,38}$ DCIP, $\mathrm{MB}$ and SKF 525-A are potent inhibitors for $n$-hexanal formation in green leaves, ${ }^{17}$ ) but these compounds at $1 \mathrm{~mm}$ did not inhibit $n$-hexanal formation by the crude extracts of alfalfa and cucumber seedlings. $p$-Chloromercuribenzoate at $0.05 \mathrm{~mm}$ did not inhibit the activity for $n$ hexanal formation.

Subcellular localization of lipoxygenase and hydroperoxide lyase in cucumber seedlings

To demonstrate subcellular localization of enzymes responsible for $n$-hexanal formation, we fractionated the subcellular components of cucumber seedlings by differential centrifugation. A $10,000 \times g$ pellet showed a little activity of hydroperoxide lyase but no activity of lipoxygenase. Most lipoxygenase activity was found in $88,000 \times g$ supernatant and hydroperoxide lyase with high specific activity was found in $88,000 \times g$ pellet. Hydroperoxide lyase was solubilized by the treatment with $0.1 \%$ Triton X-100 (Table IV). However, Triton X-100 supernatant still exhibit a little activity of lipoxygenase. The result indicates that hydroperoxide lyase is in a membrane bound form. Table $\mathrm{V}$ shows $n$-hexanal formation by the coupled reaction of $88,000 \times g$ supernatant containing lipoxygenase with Triton $\mathrm{X}-100$ supernatant containing hydroperoxide lyase. Hydroperoxide lyase pro- 
Table IV. Subcellular Localization of Lipoxygenase and Hydroperoxide Lyase in Etiolated Cucumber Seedlings

\begin{tabular}{|c|c|c|c|c|c|c|}
\hline \multirow{2}{*}{ Fraction } & \multirow{2}{*}{$\begin{array}{c}\text { Vol } \\
\text { (mll) }\end{array}$} & \multirow{2}{*}{$\begin{array}{l}\text { Protein } \\
\text { (mg) }\end{array}$} & \multicolumn{2}{|c|}{ Lipoxygenase } & \multicolumn{2}{|c|}{ Hydroperoxide lyase } \\
\hline & & & $\begin{array}{l}\text { Total } \\
\text { activity } \\
\text { (U) }\end{array}$ & $\begin{array}{l}\text { Specific } \\
\text { activity } \\
\text { (U/mg) }\end{array}$ & $\begin{array}{l}\text { Total } \\
\text { activity } \\
\text { (U) }\end{array}$ & $\begin{array}{l}\text { Specific } \\
\text { activity } \\
\text { (U/mg) }\end{array}$ \\
\hline $\begin{array}{l}88,000 \times g \\
\quad \text { supernatant }\end{array}$ & 300 & 465 & 270 & 0.58 & 1.5 & 0.03 \\
\hline $88,000 \times g$ pellet & & & & & & \\
\hline$\left\{\begin{array}{r}\text { Triton } X-100 \\
\text { supernatant }\end{array}\right.$ & 10.5 & 8.5 & 4.2 & 0.49 & 1.2 & 0.14 \\
\hline $\begin{array}{l}\text { Triton } X-100 \\
\text { pellet }\end{array}$ & 10.5 & 14.7 & 5.3 & 0.36 & 0 & 0 \\
\hline
\end{tabular}

Each fraction was prepared by the procedures as in Methods. Lipoxygenase was determined from oxygen uptake and hydroperoxide lyase was determined at $\mathrm{pH} 6.5$ from the decrease in absorbance at $234 \mathrm{~nm}$ as in Methods.

TABle V. n-HeXanal Formation from LINOLEIC ACID AND 13-HYDROPEROXYLINOLEIC ACID BY LIPOXYGENASE AND HYDROPEROXIDE LyASE from EtIOLATEd CuCUMBer SEedLINGS

\begin{tabular}{lccc}
\hline \multirow{2}{*}{ Enzyme } & \multicolumn{3}{c}{$\begin{array}{c}n \text {-Hexanal formed } \\
(\mu \text { mol/assay tube) }\end{array}$} \\
\cline { 2 - 4 } & None & $\begin{array}{c}\text { Linoleic } \\
\text { acid }\end{array}$ & $\begin{array}{c}13 \text {-Hydro- } \\
\text { peroxy- } \\
\text { linoleic } \\
\text { acid }\end{array}$ \\
\hline $\begin{array}{l}\text { Lipoxygenase } \\
\text { Hydroperoxide } \\
\text { lyase }\end{array}$ & 0.10 & 0.39 & 0.36 \\
$\begin{array}{l}\text { Lipoxygenase+ } \\
\text { hydroperoxide } \\
\text { lyase }\end{array}$ & 0.22 & 0.64 & 1.69 \\
$\begin{array}{l}\text { Lipoxygenase+ } \\
\text { hydroperoxide } \\
\text { lyase } \\
\text { (heat-denatured) }\end{array}$ & 0.25 & 2.50 & 1.54 \\
\hline
\end{tabular}

A $0.5 \mathrm{ml}$ of $88,000 \times g$ supernatant and $0.5 \mathrm{ml}$ of Triton $X-100$ supernatant in Table IV were used as an enzyme source of lipoxygenase and hydroperoxide lyase, respectively. A $0.5 \mathrm{ml}$ of $50 \mathrm{~mm}$ phosphate buffer, $\mathrm{pH} 6.5$, containing $1 \mathrm{mM}$ GSH with or without $0.1 \%$ Triton $\mathrm{X}-100$ (final concentration in reaction mixture, $0.025 \%$ ) was added to the reaction mixture of lipoxygenase or hydroperoxide lyase alone. Denatured enzymes were prepared by 10 min-heating in boiling water. $n$-Hexanal formed was determined by the headspace method $\mathrm{B}$.

duced $n$-hexanal from 13-hydroperoxylinoleic acid, but lipoxygenase could not catalyze this conversion. Linoleic acid was converted to $n$ hexanal by the combination of lipoxygenase and hydroperoxide lyase, but not by either lipoxygenase or hydroperoxide lyase. Heatdenatured enzymes could not catalyze nhexanal formation from each substrate. Moreover, cucumber lipoxygenase used in Table V was replaced by soybean lipoxygenase. These results clearly indicate that $n$-hexanal was produced via 13-hydroperoxide from linoleic acid by lipoxygenase and hydroperoxide lyase. A $88,000 \times g$ pellet also catalyzed the formation of cis-3-hexenal and trans-2-hexenal from 13hydroperoxylinolenic acid, as shown in Table IV.

\section{Purification and properties of lipoxygenase}

i) Alfalfa. Lipoxygenase was partially purified 2-fold with the recovery of $15 \%$ (Table VI). The activity for $n$-hexanal formation from linoleic acid was still found after $\left(\mathrm{NH}_{4}\right)_{2}$ $\mathrm{SO}_{4}$ fractionation, but not after CAP-S $\mathrm{S}_{1}$ cellulose chromatography. Thus, lipoxygenase could be separated from hydroperoxide lyase. Optimal pH of the enzyme was 6.5 and the enzyme was relatively stable at $\mathrm{pH} 5.0 \sim 7.5$. The ratio of 13- and 9-hydroperoxylinoleic acids produced by this enzyme was determined to be 65: 35 based on HPLC analysis (Fig. 5). This ratio was a little different from $50: 50$ reported by Chang et al. ${ }^{24}$ Alfalfa lipoxygenase was localized in a soluble fraction as well as cucumber one as it was found in 88,000 $\times g$ supernatant. 
ii) Cucumber. Lipoxygenase was purified 80 -fold with the recovery of $40 \%$ (Table VI). Lipoxygenase preparation after $\mathrm{CM}$ cellulose chromatography did not show the activity for $n$-hexanal formation from linoleic acid. Optimal pH of the enzyme was 5.5

Table VI. Summary of Purification OF LIPOXYGENASE

\begin{tabular}{|c|c|c|c|}
\hline Procedure & $\begin{array}{c}\text { Total } \\
\text { protein } \\
(\mathrm{mg})\end{array}$ & $\begin{array}{l}\text { Total } \\
\text { activity } \\
\text { (U) }\end{array}$ & $\begin{array}{l}\text { Specific } \\
\text { activity } \\
\text { (U/mg } \\
\text { protein) }\end{array}$ \\
\hline \multicolumn{4}{|c|}{ Alfalfa } \\
\hline Crude extract & 369 & 945 & 2.6 \\
\hline$\left(\mathrm{NH}_{4}\right)_{2} \mathrm{SO}_{4}$ fr. & 205 & 500 & 2.4 \\
\hline $\mathrm{CAP}_{-} \mathrm{S}_{1}$ cellulose & 27.4 & 136 & 5.0 \\
\hline \multicolumn{4}{|c|}{ Cucumber } \\
\hline Crude extract & 1764 & 525 & 0.30 \\
\hline$\left(\mathrm{NH}_{4}\right)_{2} \mathrm{SO}_{4} \mathrm{fr}$. & 1210 & 403 & 0.33 \\
\hline DEAE cellulose & 850 & 490 & 0.58 \\
\hline CM cellulose & 7.8 & 198 & 25.4 \\
\hline
\end{tabular}

Purification was started from $12 \mathrm{hr}$-old alfalfa seedlings $(22.5 \mathrm{~g})$ and 6 day-old cucumber seedlings $(72 \mathrm{~g})$. Lipoxygenase activity was determined from the absorbance change at $234 \mathrm{~nm}$.

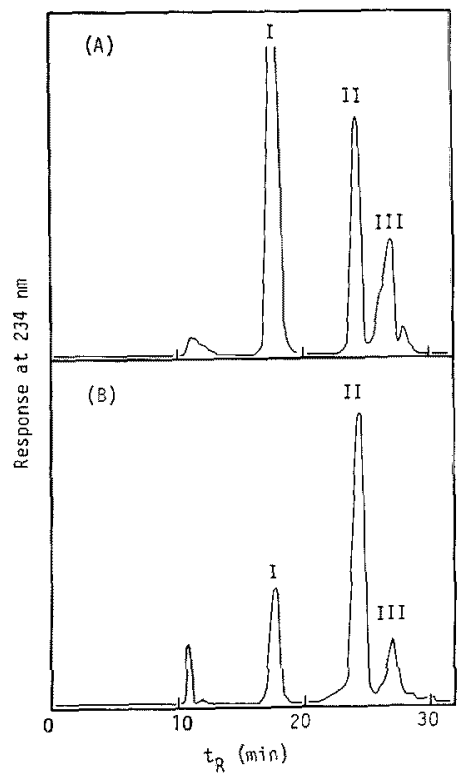

FIG. 5. HPLC of Products by Lipoxygenase Reaction of Alfalfa (A) and Cucumber (B) Seedlings.

Sample preparation and HPLC performance are shown in Materials and Methods. (I) indicates methyl linoleate; (II), methyl 13-hydroxylinoleate; and (III), methyl 9-hydroxylinoleate.
6.0 and the enzyme was stable at pH 5.5 8.0. Apparent $\mathrm{Km}$ value for linoleic acid was $0.11 \mathrm{~mm}$ at $25^{\circ} \mathrm{C}$. The ratio of 13 - and 9. hydroperoxylinoleic acids as products was 85:15 (Fig. 5).

\section{Properties of hydroperoxide lyase}

Hydroperoxide lyase, which catalyzed nhexanal formation from 13-hydroperoxylinoleic acid and cis-3-hexenal from 13-hydroperoxylinolenic acid (Tables III and V), was a membrane bound enzyme and it was solubilized by the treatment with Triton $\mathrm{X}-100$ described above in cucumber seedlings (Table. IV) However, the possibility that the hydroperoxide lyase activity determined from decrease in the absorbance at $234 \mathrm{~nm}$ (Table IV and Figs. 1 and 2) contains in part hydroperoxide isomerase activity can not be excluded. ${ }^{25 \sim 30}$ ? Optimal pH of hydroperoxide lyase in the crude extracts was $\mathrm{pH} 6 \sim 7$ both for alfalfa and cucumber. Alfalfa hydroperoxide lyase showed a high activity with 13-hydroperoxide as a substrate, but not with 9-hydroperoxide (Table I). In contrast, cucumber enzyme was active with both 9-and 13-hydroperoxides.

\section{DISCUSSION}

Although $n$-hexanal formation from linoleic acid in etiolated watermelon seedlings is reported, "the enzymatic properties of this biosynthetic pathway and $\mathrm{C}_{6}$-aldehyde formation from linolenic acid in etiolated seedlings have not been well established. We have inclusively shown in this paper that $n$-hexanal and cis-3hexenal (which isomerizes easily to trans-2hexenal) are produced via 13-hydroperoxides from linoleic acid and linolenic acid, respectively, in etiolated alfalfa and cucumber seedlings, and have characterized some properties of lipoxygenase and hydroperoxide lyase as the enzymes responsible for $\mathrm{C}_{6}$-aldehyde formation in etiolated seedlings.

The changes in $n$-hexanal formation from linoleic acid, lipoxygenase and hydroperoxide lyase activities during germination paralleled both in alfalfa and cucumber: $n$-hexanal for- 
mation occurred when lipoxygenase and hydroperoxide lyase activities appeared (Figs. 1 and 2). Cucumber showed the maximal activities the $6 \sim 7$ th day of germination but not in dry seeds, being a pattern similar to that of watermelon. ${ }^{7}$ In contrast, alfalfa showed the maximal activities in dry seeds and 1st-2nd day of germination. Thus, the two types of patterns of the activity changes were observed. A similar enzyme system for $n$-hexanal formation from linoleic acid during germination seemed to occur in a wide range of plants, as we observed the $n$-hexanal formation from linoleic acid in some leguminous and other plants (unpublished data).

From the analysis of essential oil as in Table I, $n$-hexanal was found to be a main volatile product both from linoleic acid and its 13-hydroperoxide in alfalfa and cucumber. On the other hand, trans-2-nonenal was produced from 9-hydroperoxylinoleic acid in cucumber seedlings, but not in alfalfa seedlings. These suggest that hydroperoxide lyase of cucumber seedlings utilized 13- and 9-hydroperoxides as a substrate to yield $n$-hexanal and trans-2-nonenal, respectively, like that of cucumber fruits ${ }^{10 \sim 13\}}$ and that alfalfa hydroperoxide lyase utilized 13-hydroperoxide, but not 9-hydroperoxide like tomato fruits. ${ }^{8}$ Main products of lipoxygenase reaction were 9- and 13-hydroperoxylinoleic acids for alfalfa seedlings and 13-hydroperoxide for cucumber seedlings, as shown in Fig. 5. Hence, although 9- and 13-hydroperoxylinoleic acids were produced from linoleic acid by lipoxygenase in the crude extract of alfalfa seedlings, hydroperoxide lyase could cleave only 13-hydroperoxide of both to yield $n$-hexanal. In contrast, in the crude extract of cucumber seedlings, hydroperoxide lyase cleaved the 13-hydroperoxide, which was a sole product of lipoxygenase reaction to yield $n$-hexanal though cucumber hydroperoxide lyase utilized 9- and 13-hydroperoxides.

$n$-Hexanal formation from linoleic acid and its 13-hydroperoxide was also confirmed by the headspace method in alfalfa and cucumber (Fig. 3). When linolenic acid was used as a substrate, cis-3-hexenal was produced from linolenic acid and its 13-hydroperoxide by the crude extracts of alfalfa and cucumber seedlings. From the results of Tables II and IV and Fig. 4, it was established that cis-3-hexenal was at first produced as a $\mathrm{C}_{6}$-aldehyde from linolenic acid. Observation of hydroperoxide formation during $\mathrm{C}_{6}$-aldehyde formation from $\mathrm{C}_{18}$-fatty acids by the crude extracts of alfalfa and cucumber seedlings (Fig. 3 and Table II) strongly supports the role of 13-hydroperoxides as an intermediate and involvement of lipoxygenase and hydroperoxide lyase in the crude extracts.

Lipoxygenase was partially purified from etiolated alfalfa and cucumber seedlings and hydroperoxide lyase from cucumber seedlings as the enzymes responsible for $\mathrm{C}_{6}$-aldehyde formation. Lipoxygenase was obtained in a soluble fraction. On the other hand, hydroperoxide lyase was in a membrane bound form in cucumber seedlings as shown in Tables III and IV. The hydroperoxide lyase in this paper seemed to be the same type of enzyme as reported in watermelon seedlings ${ }^{7 /}$ and cucumber fruits: ${ }^{12,13)}$ watermelon enzyme was reported to be eluted near the void volume on Sephadex G-200, and cucumber fruit one was localized in, at least, the plasma and Golgi membrane. Hydroperoxide lyase of alfalfa seedlings may be also in a membrane bound form.

From the substrate specificity and products of lipoxygenase and hydroperoxide lyase as described in this paper, coupled reaction of these enzymes results in $\mathrm{C}_{6}$-aldehyde formation from $\mathrm{C}_{18}$-unsaturated fatty acids (linoleic acid and linolenic acid) via their 13-hydroperoxides. The proposed biosynthetic pathway for $\mathrm{C}_{6}$ aldehydes and the related enzymes are summarized in Scheme I. $\mathrm{C}_{9}$-Aldehyde formation is also summarized in Scheme $\mathrm{I}$, in which compounds in parentheses have not been confirmed in etiolated cucumber seedlings. But trans-2-nonenal is produced in cucumber seedlings mainly when 9-hydroperoxylinoleic acid is used as a substrate, but not linoleic acid (Table I). trans-2-Nonenal formed from 


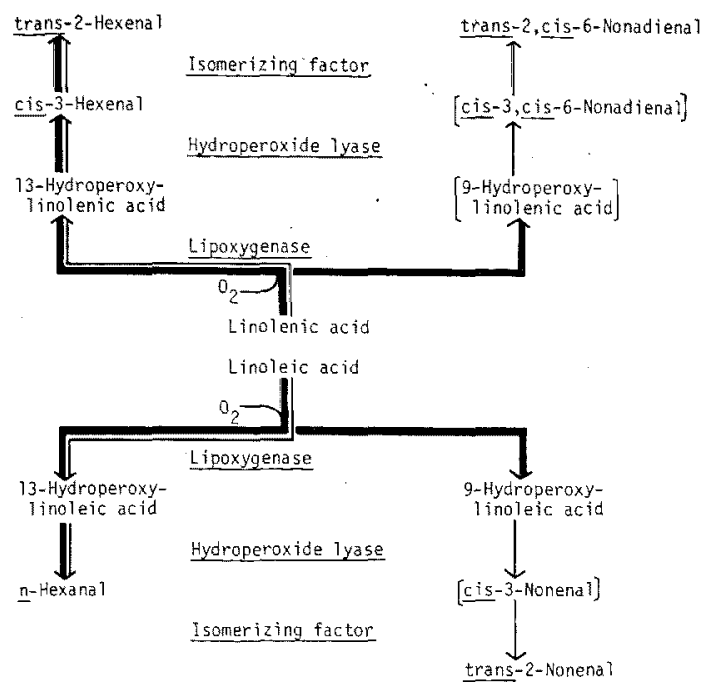

SCHeme 1. Proposed Biosynthetic Pathway of $\mathrm{C}_{\mathrm{B}^{-}}$ and $\mathrm{C}_{9}$-Aldehydes from $\mathrm{C}_{18}$-Unsaturated Fatty Acid in Etiolated Seedlings.

Alfalfa $(-\infty)$, cucumber $(-)$.

9-hydroperoxylinoleic acid by the crude homogenate of cucumber seedlings may be a isomerized product of cis-3-nonenal as well as in cucumber fruits. ${ }^{12,14,31}$ ) In the same manner the crude homogenate may give trans-2, cis-6nonadienal via cis-3, cis-6-nonadienal from 9hydroperoxylinolenic acid. ${ }^{12,14,313}$ The fact that $\mathrm{C}_{9}$-aldehydes are main products from linoleic acid and linolenic acid in cucumber fruits ${ }^{10,11,14,15)}$ may be caused by the difference in products of lipoxygenase reaction in fruits and seedlings.

Recently, we reported the $\mathrm{C}_{6}$-aldehyde formation from $\mathrm{C}_{18}$-unsaturated fatty acids in green leaves such as tea ${ }^{6,17 \sim 19,32 \sim 36)}$ and $\mathrm{Far}^{2}$ fugium japonicum. ${ }^{37 \sim 39)}$ However, the enzymes responsible for $\mathrm{C}_{6}$-aldehyde formation in etiolated seedlings are different from those in green leaves in some points: subcellular localization of the enzymes, behavior of 13-hydroperoxides of $\mathrm{C}_{18}$-fatty acids and inhibition by some drugs etc.

Acknowledgments. This work was supported in part by the research grant from the Ministry of Education of Japan and from the Agricultural Chemical Foundation of Japan. We wish to express our thanks to Smith Kline \& French Labs, Philadelphia, for their kind gift of SKF 525-A and also to Toyo Pulp Co.,
Ltd., Tokyo, for their gift of CAP-S 1 cellulose. We thank Miss M. Ogawa and Mr. A. Kitamura for their skilled technical assistance.

\section{REFERENCES}

1) F. Drawert, W. Heiman, R. Rmberger and R. Tressl, Ann. Chem., 694, 200 (1968).

2) S. J. Kazeniac and R. M. Hall, J. Food. Sci., 35, 519 (1970).

3) R. Saijyo and T. Takeo, Plant Cell Physiol, 13, 991 (1972).

4) S. Jadhave, B. Singh and D. K. Salunke, ibid., 13, 449 (1972).

5) J. G. Gonzalez, P. Coggon and G. W. Sanderson, J. Food Sci., 37, 797 (1972).

6) A. Hatanaka and T. Harada, Phytochemistry, 12, 2341 (1973).

7) B. A. Vick and D. C. Zimmerman, Plant Physiol., $57,780(1976)$

8) T. Galliard and J. A. Matthew, Phytochemistry, 16, 339 (1977)

9) J. A. Matthew and T. Galliard, ibid., 17, 1043 (1978).

10) T. Galliard and D. R. Phillips, Biochim. Biophys. Acta, 431, 278 (1976).

11) T. Galliard, D. R. Phillips and J. Reynolds, ibid., 441, 181 (1976).

12) D. R. Phillips and T. Galliard, Phytochemistry, 17, 335 (1978)

13) D. A. Wardale, E. A. Lambert and T. Galliard, ibid., 17, 205 (1978).

14) A. Hatanaka, T. Kajiwara and T. Harada, ibid., 14, 2589 (1975).

15) J. Sekiya, T. Kajiwara and A. Hatanaka, ibid., 16, 1043 (1977).

16) K. Surrey, Plant Physiol, 39, 65 (1964).

17) A. Hatanaka, J. Sekiya, T. Kajiwara and T. Miura, Agric. Biol. Chem., (in preparation).

18) T. Kajiwara, T. Harada and A. Hatanaka, ibid., 39, 243 (1975).

19) J. Sekiya, S. Numa, T. Kajiwara and A. Hatanaka, ibid., 40, 185 (1976).

20) J. Sekiya, H. Aoshima, T. Kajiwara, T. Togo and A. Hatanaka, ibid., 41, 827 (1977).

21) T. Galliard and D. R. Phillips, Biochem. J., 124, 431 (1971).

22) M. Hamberg and B. Samuelsson, J. Biol. Chem., 242, 5329 (1967).

23) O. H. Lowry, N. J. Rosebrough, A. L. Farr and R. J. Randall, ibid., 193, 265 (1951).

24) C. C. Chang, W. J. Esselman and C. O. Clagett, Lipids, 6, 100 (1971).

25) D. C. Zimmerman, Biochem. Biophys. Res. Commum,, 23, 398 (1966)

26) D. C. Zimmerman and B. A. Vick, Plant Physiol., 46, $445(1970)$. 
27) G. A. Veldink, J. F. G. Vligenthart and J. Boldingh, Biochem. J., 120, 55 (1970).

28) H. W. Gardner, J. Lipid Res., 11, 311 (1970).

29) W. J. Esselman and C. O. Clagett, ibid., 15, 173 (1974).

30) S. Yabuuchi, Nippon Nôgeikagaku Kaishi, 52, 417 (1978).

31) T. Kajiwara, Y. Odake and A. Hatanaka, Agric. Biol. Chem., 39, 1617 (1975).

32) A. Hatanaka, T. Kajiwara and J. Sekiya, Phytochemistry, 15, 1889 (1976).

33) J. Sekiya, T. Kajiwara and A. Hatanaka, Plant Cell Physiol., 18, 283 (1977).
34) A. Hatanaka, T, Kajiwara, J. Sekiya and Y. Kido, Phytochemistry, 16, 1828 (1977).

35) A. Hatanaka, J. Sekiya and T. Kajiwara, ibid., 17, 869 (1978).

36) A. Hatanaka, T. Kajiwara, J. Sekiya and K. Fujimura, Agric. Biol. Chem., 43, 175 (1979).

37) A. Hatanaka, T. Kajiwara, J. Sekiya and H. Hirata, ibid., 40, 2177 (1976).

38) A. Hatanaka, J. Sekiya and T. Kajiwara, Plant Cell Physiol., 18, 107 (1977).

39) J. Sekiya, T. Kajiwara and A. Hatanaka, ibid, 19, 553 (1978). 